\title{
SISTEMAS DE HIPERMEDIOS: DESARROLLO Y CONFIGURACION
}

\author{
Purificación Moscoso
}

\begin{abstract}
Resumen: Resume la historia del desarrollo de los sistemas de hipertexto y de hipermedios, y explica dichos conceptos. Se centra en el desarrollo de los sistemas de hipermedios, en su configuración y funcionalidad, en la organización de la información y en los principales problemas que entrañan. La explicación teórica se complementa con la presentación de dos proyectos de hipermedios: American Memory y Project Emperor-I.

Palabras clave: hipertexto, sistemas de hipermedios, American Memory, Project Emperor-I.
\end{abstract}

\begin{abstract}
Summary of the historical development of hypertext and hypermedia systems, and explanation of both concepts. Introduction to the development of hypermedia systems, configuration, functionality and organization of the information stored, as well as the major problems they present. As an example of hypermedia systems two projects are presented: American Memory and Project Emperor.I.

Keywords: hypertext, hypermedia systems, American Memory, Project Emperor-I.
\end{abstract}

\section{Introducción}

Durante los últimos años, el mundo de la biblioteconomía y la documentación se ha visto alterado por la irrupción de nuevos medios de almacenamiento de la información. Por otro lado, ideas que nacieron en los años cuarenta, y que se han desarrollado desde los sesenta, han dado lugar, en los ochenta, a nuevas formas de estructuración de la información. Nuevas tecnologias y nuevas ideas organizativas han hecho posible el desarrollo de proyectos de hipertex to y de hipermedios que han revolucionado el sistema de organización y recuperación de la información.

Este artículo es una introducción a los sistemas de hipermedios: su organización, configuración, diseño y principales problemas que plantean. La explicación teórica de estos sistemas se ejemplifica con dos aplicaciones: "American Memory", en el ámbito de las bibliotecas, y "Project Emperor-I", en el de las humanidades.

Los sistemas de hipermedios son una extensión de los sistemas de hipertexto, cuyos origenes se remontan a 1945 .

\section{Historia del concepto hipertexto}

Cómo organizar la masiva cantidad de información que empezaba a generarse al finalizar la segunda guerra mundial fue lo que llevó a Vannevar Bush, en 1945, a proponer un sistema no lineal de estructuración de la información que se correspondiera con la naturaleza asociativa de la mente humana. Ideó el sistema "memex" (memory extender system), que describió en su famoso artículo "As we may think" (1). "Memex" proporcionaba acceso a grandes colecciones de microfilms y a mecanismos para crear vínculos o ligaduras entre partes de información relacionada dentro del sistema. Los usuarios podrian hojear y acceder a los documentos mediante instrucciones del ordenador terminal. Aunque el sistema "memex" nunca se llegó a desa-

\footnotetext{
Simons College, Graduate School of Library and Information Science. Boston Ma. EE. UU
}

Recibido 6-3-90 
rrollar, la idea de utilizar ordenadores para almacenar asociaciones entre distintas piezas de información dio lugar, veinte años más tarde, a las primeras experimentaciones sobre sistemas de hipertexto.

Engelbart, influido por la idea de "memex", creó en 1963 el sistema NLS (oN Line System), que contenía muchos de los conceptos e ideas de lo que después sería un sistema de hipertexto (por ejemplo: ratón, ventanas y capacidad para crear asociaciones) (2). Dicho sistema consistia en ficheros de información organizados en segmentos de hasta 300 palabras relacionados tanto jerárquicamente como no (3). También en los años sesenta, Ted Nelson comenzó a trabajar en el proyecto Xanadu, un sistema de ordenador diseñado para crear enlaces que organizaran grandes cantidades de información en linea (4). Fue Ted Nelson quien acuñó la palabra "hypertext". Definió el término "hyper" como "extendido, generalizado, y multidimensional" y "hypertext" como "iectura y escritura no secuencial" (5).

Con la comercialización, en 1987, de los programas "HyperCard" y "Guide", (Guide, comercializado por Owl International Inc. cuenta con las versiones para IBM y Macintosh. Su precio es \$99. HyperCard, diseñado por Bill Atkinson, sólo corre en Macintosh. Viene incluido con la compra de cualquier Macintosh; y su precio, para los que lo compraron antes de 1987, es \$49) la posibilidad de crear proyectos de hipertexto dejó de estar reducida a grandes laboratorios y empresas. Con ambos softwares, los usuarios de microordenadores, tanto Macintosh como IBM o compatibles, pueden diseñar sus proyectos de hipertexto.

\section{Concepto y definición de "hipertexto"}

En un sentido general, y tal y como lo definió Nelson, "hipertexto" significa una lectura y escritura no lineal. El término "hipertexto" hace referencia a la organización y recuperación de información textual mediante enlaces que asocian palabras, frases o documentos completos con información del mismo o de otros documentos. La estructuración de un sistema de hipertexto puede representarse en forma de una red donde los distintos nudos corresponden a toda parte informativa susceptible de ser asociada, y los enlaces, a asociaciones especificas entre las distintas partes de información. Así, cualquier palabra, frase, párrafo, etc. puede ser, según esta idea, un nudo, si aparece asociado, mediante un enlace o vínculo, con otras palabras, frases, párrafos... Del mismo modo, un sistema de hiperaudio sería la conexión asociativa entre secuencias digitales de sonido, ya sea éste voz o música; o un sistema de hipergráfico la conexión asociativa de gráficos de ordenadores en dos y' tres dimensiones o secuencias animadas, entre si.

Esta idea de crear asociaciones entre distintas partes de información relacionada entre si la encontramos ya en las tradicionales fichas de referencia de los catálogos de las bibliotecas ("Véase" y "Véase además"). Tambièn en las notas a pie de página y referencias bibliográficas de los documentos escritos. La diferencia estriba en que en un sistema de hipertexto el usuario no tiene que pasar páginas, localizar el documento, encontrar la página o páginas a la que se refiere la nota del documento inicial, buscar definiciones de términos que desconoce... Todo, documentos, referencias, bibliografia y definiciones forman un mismo documento electrónico (Figura 1). El usuario 
puede ir y volver, hojear, encontrar rápidamente la parte de información relacionada, etc., mediante la activación de una instrucción de ordenador.

Actualmente existen dos clases de hipertexto: estático y dinámico (6). El hipertexto estático no permite al usuario cambiar la base de datos, mientras que en el dinámico pueden añadirse o suprimirse datos y enlaces asociativos, en áreas especialmente diseñadas para ello. El usuario, además de recuperar información de una forma no lineal, puede añadir o suprimir, crear sus propias asociaciones, incluir sus comentarios, etc.

Pigura 1

Enlaces creados entre distintas partes de información (nudos) de tres documentos textuales, referencias bibliográficas, bibliografía y definiciones de términos.

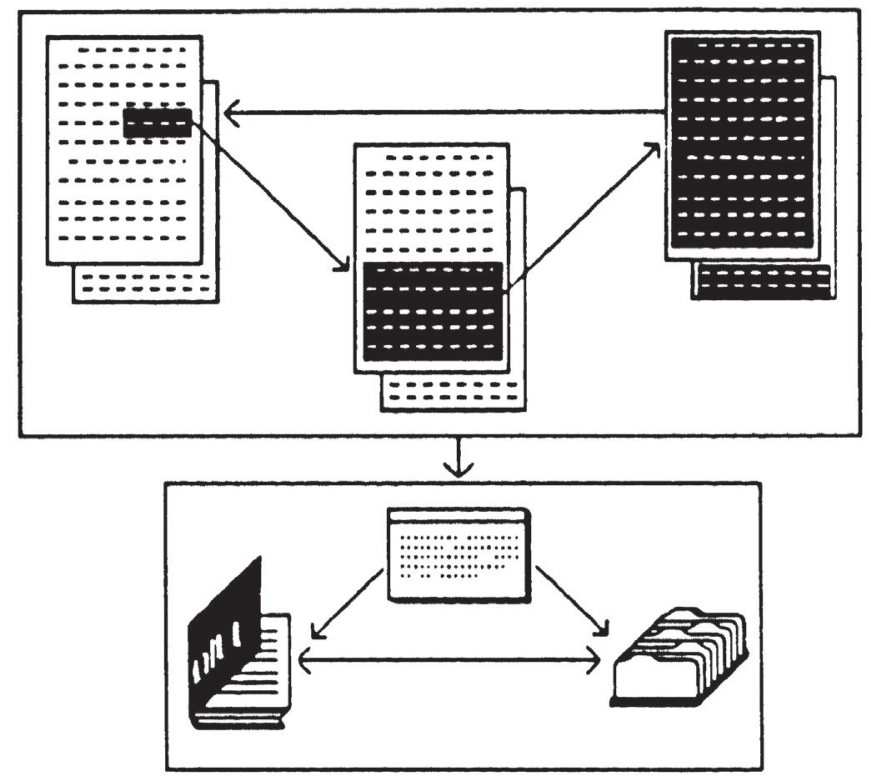

\section{Sistemas de hipermedios. Concepto y definición.}

Las aplicaciones de hipertexto estructuran información básicamente textual e incluyen algunos gráficos digitalizados. Sin embargo, dado que sonido, texto, gráficos e imágenes son codificables en señales digitales, la tecnologia actual permite integrarlos todos en un único sistema de información. Asi, si en lugar de sólo texto (y gráficos), o sólo música, o sólo imágenes, tenemos información gráfica, visual, sonora y textual, estamos ante un sistema de hipermedios. Los sistemas de hipermedios incluyen cualquier clase de información que pueda ser codificada digitalmente para el almacenamiento y recuperación a través de sistemas de ordenadores: imágenes (en movimiento y estáticas), voz, música, gráficos, animación y texto (figura 2). En una estructura de hipermedios los nudos, además de partes de un documento escrito (o documentos en toda su extensión), son también sonidos, imágenes y gráficos. 
Figura 2

Enlaces entre información de todo tipo de medios, controlados por un microordenador

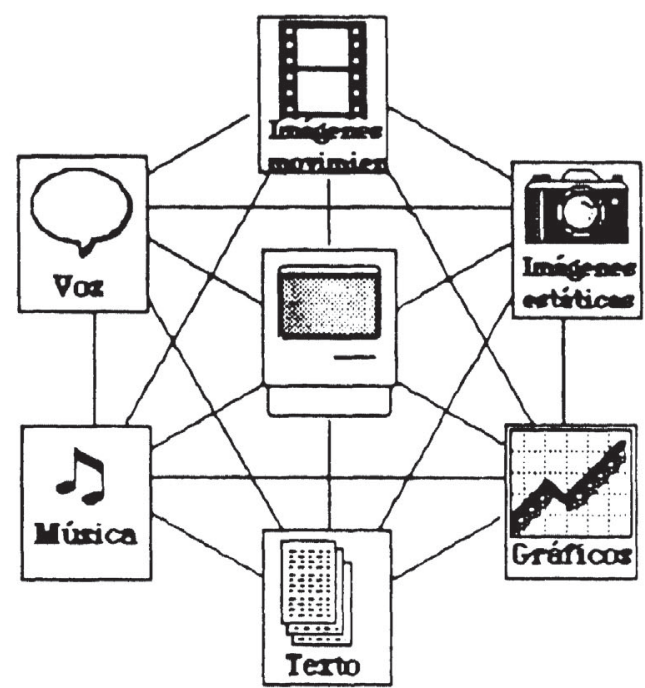

El término "hipermedios" significa, pues, la organización de información textual, gráfica y sonora mediante enlaces que crean asociaciones entre información relacionada dentro del sistema, mediante la integración de todo tipo de tecnologias, tradicionales y nuevas.

\section{Configuración y funcionamiento de un sistema de hipermedios}

Almacenar información de múltiples medios, organizarla mediante sistemas asociativos y recuperarla a través de los enlaces relacionales creados, requiere la integración de cuatro subsistemas: sistema de hardware, sistema de información, sistema de software y sistema de comunicaciones (7).

El sistema de hardware proporciona el soporte físico necesario para la configuración del sistema. Se compone de los siguientes elementos:

- microordenador de al menos 1 MB de memoria

- lector/es de disco/s óptico/s

- monitor para la recuperación de texto y gráficos

- pantalla para la recuperación de imágenes y vídeo

- altavoces para la recuperación de información sonora

- teclado para la introducción del texto

- ratón, palanca de mando o pantalla de tacto para la selección en pantalla de la información requerida.

El sistema de información proporciona los soportes necesarios para el almacenamiento de la información sonora, textual, gráfica y visual. Estos soportes son:

- disco magnético para el almacenamiento de información variable (texto y gráficos) y de los enlaces asociativos.

- disco/s óptico/s para el almacenamiento de información no variable: imágenes (estáticas y en movimiento), gráficos, texto y sonido. Tradicionalmente el videodisco almacenaba información visual, y el CDROM información textual. Sin embargo, el desarrollo de nuevas 
tecnologias de multimedios, CD-I, DVI y CD-ROM XA (8), hace posible la integración de información textual, sonora y visual en un mismo soporte.

El sistema de software lo forman el utilizado (HyperCard, Guide, SuperCard, etc.) y el programa desarrollado para la aplicación precisa. Así, por ejemplo, utilizando HyperCard y su lenguaje de programación HyperTalk, se desarrollaria el programa necesario para llevar a cabo una aplicación determinada. Los segmentos o elementos requeridos en el diseño del programa son los siguientes:

- Indización de todo el material almacenado en los distintos medios: videodisco, CD-ROM, disco duro, etc.

- Mapa global que explique visualmente el acceso al material en los distintos medios.

- Enlaces asociativos usando el indice, mapa y estructuras de enlace que permiten al usuario moverse a través del material almacenado.

- El punto de vista o perspectiva que han generado las distintas estructuras asociativas para que el usuario pueda crear nuevas formas de acceder al material almacenado.

- Controlador de vídeo para acceder a las imágenes almacenadas.

- Controlador de sonido para acceder a las secuencias sonoras almacenadas.

El sistema de comunicaciones se compone de redes, locales y remotas, que proporcionan acceso a otros sistemas de información.

La sintesis de estos cuatro subsistemas proporciona la configuración básica de un sistema de hipermedios.

Las nuevas tecnologias de almacenamiento y recuperación de información y los sistemas de ordenadores de alta potencia apenas presentan limitaciones técnicas para la configuración de los sistemas. Sin embargo, la funcionalidad del sistema no sólo depende de la tecnología disponible. La sintesis de subsistemas antes señalados brinda tan sólo posibles capacidades técnicas, que se convierten en reales cuando en el diseño del sistema se tienen en cuenta determinadas premisas. Gainers y Vickers dividen estas premisas en esenciales, esperadas y deseadas (7). Premisas esenciales son aquéllas sin las cuales el sistema no puede considerarse un sistema de hipermedios. Sin las premisas esperadas la funcionalidad del sistema quedaría muy limitada. Y con las deseadas el sistema se convertiria en un buen ejemplo de sistema de hipermedios.

Para que el sistema se pueda considerar de hipermedios tiene que proporcionar entradas que permitan la asociación de información (notas a pie de página, referencias bibliográficas o citas son ejemplos de entradas en los documentos escritos); permitir a los usuarios hojear y desplazarse por el sistema a través de enlaces no predeterminados; proporcionar múltiples perspectivas de la información almacenada, asi como permitir el establecimiento de otras nuevas; y facilitar el acceso a la información en lugar de hacerlo más complicado.

Del sistema se espera que integre diversos medios (textuales, graficos, visuales y sonoros); que esté abierto a la incorporación de nueva información; que posibilite el acceso de usuarios de diversas condiciones; y que permita al usuario entender la organización de la información almacenada en términos espaciales (es decir, que para entender la estructuración pueda recurrir a 
conceptos como "pirámide demográfica", "árbol genealógico", "niveles de conocimiento", "infraestructura", y otras metáforas del pensamiento espacial).

Y, por último, se desea que: sea programable y admita la incorporación de nuevos programas; proporcione al usuario la información y ayuda necesarias para que no se pierda (uno de los principales problemas de los sistemas de hipermedios); guie al usuario para que éste pueda establecer las bases de su elección; y le permita comprobar las fuentes de información.

\section{Organización de la información}

La información es a la vez generadora del conocimiento y resultado de éste. Estos dos aspectos han de tenerse en cuenta a la hora de buscar una forma de organizarla. Si admitimos que la naturaleza del conocimiento humano es menos lineal que relacional, podemos deducir que una forma relacional de organizar la información es más adecuada que una organización lineal para generar conocimiento. Por lo tanto, el modelo de organización de la información debe estar inspirado en un modelo de representación simbólica del conocimiento, algo que ha preocupado a la ciencia de la documentación desde sus origenes. Sin embargo, analizar y profundizar en los distintos tipos de modelos de representación del conocimiento es algo que excede en mucho el próposito de introducción de este artículo. En este apartado se of rece sólo una idea general acerca de las directrices o pautas que marcan la organización de la información en los sistemas hipermedios.

La forma tradicional de transmitir la información (documentos escritos) y las limitaciones tecnológicas impusieron durante mucho tiempo una organización de la información $y$, por tanto, una recuperación básicamente lineal. Hasta la llegada de la lógica de Boole, salvo pequeñas asociaciones por medio de referencias, el modo de organización y recuperación de información era predominantemente lineal. El sistema de operadores booleanos, que posibilitaba una recuperación asociativa de la información, rompió esta linealidad. La estructuración de la información pasó a adquirir relaciones bidimensionales, verticales (relaciones jerárquicas) y horizontales (entre términos relacionados) por medio de lerguajes documentales, especialmente tesauros. Bush, con su idea de emular mediante el sistema "memex" la naturaleza asociativa de la mente humana (1), abrió las puertas a una estructuración de la información multidimensional. Asi, manteniendo esta metáfora geométrica, el sistema de organización de la información ha estado concebido, a lo largo de su historia, en una recta, en un plano y, ahora, en un espacio multidimensional.

Los sistemas de hipermedios permiten recuperar información de una forma multidimensional. Un sistema de hipermedios es un sistema de comuncación y su riqueza radica en las relaciones que se establecen entre la información almacenada. Las asociaciones son características de todo sistema de comunicaciones. En el lenguaje humano, por ejemplo, se establecen, principalmente, dos tipos de asociaciones: paradigmáticas (entre conceptos relacionados semánticamente) y sintagmáticas (entre segmentos informativos relacionados sintácticamente). En los lenguajes documentales se predeterminan relaciones jerárquicas y relaciones asociativas. Sin embargo, la mente asocia ideas en múltiples dimensiones, estableciendo relaciones en todo tipo de direcciones. Esta red de posibles asociaciones multidimensionales es la que determina la organización de la información en los sistemas de hipermedios. Y la estructura 
de enlaces diseñada es la que determina el modo de recuperación de la información. Esto no significa que se trate de un sistema cerrado, pues, como ya se ha dicho, el sistema debe estar abierto, esto es, permitir al usuario crear sus propias y nuevas asociaciones.

La estructuración de la información en los sistemas de hipermedios es similar a la de una red semántica, que es un modelo de representación del conocimiento. Los nudos representan conceptos 0 ideas y los enlaces relaciones entre éstos. Al igual que las redes semánticas, los sistemas de hipermedios también consisten en nudos y enlaces. Son más flexibles que los sistemas tradicionales de estructuración de la información, en parte debido a que la información que contienen se presenta en todo tipo de medios. Así, un nudo puede consistir en un fragmento de texto, en una palabra, o en un texto completo; en una imagen completa o parte de ella; en un gráfico o en cada una de sus partes; en un sonido, etc. Utilizando el sot tware HyperCard, por ejemplo, para el diseño del programa del sistema, los nudos estarían representados por "botones" (traducción literal del término inglés "button") que pueden ser programados (en el apartado "script") para la creación de los enlaces que son los que definen la relación entre los nudos. Los enlaces definen la estructura de los sistemas de hipermedios y proporcionan la capacidad de hojear y explorar los nudos informativos. Estos pueden usarsu para distintos propósitos: conectar comentarios y anotaciones con la fuente a la que van dirigidos, establecer la relación existente entre dos piezas informativas, etc. (9), y pueden clasificarse en distintos tipos. Sin embargo, no hay que olvidar que cualquier clasificación significa simplificación y reducción, y, en cierta manera, inflexibilidad. Un sistema de hipermedios es, en su esencia, un sistema abierto a múltiples perspectivas e interpretaciones del conocimiento, por lo que cualquier clasificación que se haga de su estructuración debe tomarse tan sólo como meramente orientativa, y teniendo siempre en cuenta que otras muchas son posibles. Una posible clasificación sería: enlaces de desplazamiento y enlaces organizativos, cada uno de ellos subdividido a su vez en varias categorías.

Los enlaces de desplazamiento permiten al usuario desplazarse por el sistema con un movimiento semejante al que llevaria a cabo con una cámara de vídeo (10): grabar una escena desde diversas tomas, volver atrás y adelante; aumentar, mediante un zoom, una determinada parte de la escena para después volver a la dimensión original de ésta. Asi, mediante los enlaces de movimiento el usuario puede trasladarse a través de los distintos nudos informativos relacionados, posibilitándosele el movimiento a través del sistema. Los enlaces de expansión le capacitan para ampliar información; es decir, para pasar de un resumen a la fuente primaria a la que hace referencia; de una ciudad localizada en un mapa a un mapa ampliado de dicha ciudad; de un detalle de una fotografia a su ampliación correspondiente, etc. Los enlaces de retroexpansión representan la función inversa a los anteriores, es decir, presentan al usuario una visión generalizada de la parte informativa requerida.

Los enlaces organizativos se refieren a la organización de las distintas partes de la información o nudos, y pueden categorizarse en jerárquicos relacionales y de indización.

Los enlaces ierárquicos establecen relaciones de jerarquia entre los nudos y se corresponden con el modelo de "superconcepto" en la teoría de red 
semántica. Los enlaces jerárquicos conectan un nudo "padre" con su "hijo" formando una cadena en forma de árbol.

Los enlaces relacionales organizan la información de un modo no jerárquico, sino relacional. Establecen las asociaciones entre los distintos nudos informativos relacionados entre sí. Los nudos pueden ser textuales, gráficos, visuales y sonoros; pueden consistir en documentos enteros o en partes de documentos; pueden ser fuentes primarias o secundarias, etc. Los tipos de relaciones creadas entre ellos responden a las distintas clases de relaciones que se establecen en los modelos de estructuración relacional del conocimiento, que indican la relación existente entre las distintas partes enlazadas: causalidad, posesión, etc.

Los enlaces de indización crean una vinculación implicita. Además de la vinculación explícita creada por los enlaces referenciales y jerárquicos, existe una clase de vinculación implicita creada a través del uso de palabras clave y/o descriptores, mediante la cual el usuario puede recuperar información relacionada con un determinado concepto o conceptos.

Para representar enlaces, texto, gráficos, imágenes y sonido, Nelson propone un esquema en el que quepan "todos los tipos de enlaces que uno pueda pensar" si bien "ciertas formas de enlaces-tipo agrupativos son deseables" (11). $\mathrm{Su}$ idea de sistema hipermedio se identifica con un sistema abierto, esto es, con un sistema donde los distintos usuarios puedan añadir información, anotar $y$, por tanto, crear sus propias asociaciones.

Hasta aquí he of recido una visión teórica de la configuración, funcionalidad y organización de los sistemas hipermedios. Lo que sigue es una descripción de dos aplicaciones concretas a campos diferentes: el de las bibliotecas y el de las humanidades. Esta exposición complementa la explicación teórica, y servirá para que el lector se haga una idea clara acerca de esta nueva forma de estructurar y transmitir información.

\section{American Memory}

Un ejemplo de sistema de hipermedios creado para organizar y difundir colecciones de información conservadas en bibliotecas es el proyecto American Memory, de la Biblioteca del Congreso de Estados Unidos (12). Su objetivo es distribuir y transmitir las colecciones contenidas en esta biblioteca a otras bibliotecas e instituciones, mediante el uso de tecnologias ópticas. El proyecto, que durante 1989 ha estado en fase de planificación, empieza en 1990 un periodo de prueba de seis años. American Memory pretende servir de ejemplo a otras bibliotecas y centros de información sirviendo de puente a la biblioteca del futuro, y contribuyendo al diseño de la biblioteca electrónica.

La información que se almacenará en el sistema se compone de las colecciones de manuscritos, discos, libros, películas y materiales gráficos y fotográficos de la Biblioteca del Congreso. Las colecciones se agruparán en series temáticas, subdivididas, a su vez, en varias subseries. Por el momento, las series que se van a incluir son las siguientes:

I.Gentes y lugares de América: documentos e imágenes

II. Expresion cultural americana: textos e imágenes que representan las artes. 
III. Legislatura americana: fuentes para el estudio de la historia del Congreso de los Estados Unidos.

Por un lado, el almacenamiento óptico de las colecciones hace que a éstas pueda acceder todo tipo de público, no sólo investigadores. Por otro, el modo en el que la información está organizada hace que su recuperación se adapte a las distintas necesidades de cada grupo de usuarios: desde investigadores hasta el público general (la serie "Gentes y lugares de América" está pensada, sobre todo, para esta última clase de usuarios). El diseño del sistema admite búsqueda booleana, manipulación de la información recuperada en el área creada para ello, impresión de las imágenes y texto recuperados, combinación de distintos tipos de información (por ejempio, una imagen puede ir acompañada de una explicación textual), etc.

El hardware del sistema prototipo se compone de un microordenador Mac $I I x$ (corre en cualquier ordenador de la serie Mac II), un lector de CD-ROM, un lector de videodisco y una impresora. El diseño del programa se ha realizado con HyperCard. La información almacenada en los discos CD-ROM es, por un lado, el catálogo mediante el cual los usuarios pueden buscar y seleccionar los temas de su interés; y, por otro, imágenes y textos digitalizados.

El catálogo se compone de registros bibliográficos MARC (o del tipo MARC) que of recen una visión amplia, y a veces detallada, sobre el contenido del American Memory. El usuario, en un plazo de tiempo más largo, podrá también hacer búsquedas usando tesauros específicos y texto libre, que le of recerán un acceso más detallado a colecciones particulares. Aunque se pueda recuperar información a traves de autores y titulos, el sistema está diseñado para maximizar la habilidad del usuario en la búsqueda por materias.

El sistema de búsqueda e indización de American Memory respondera a las preguntas de los usuarios con resúmenes organizados y jerarquizados de lo que pueden encontrar en el catálogo.

Una vez que el usuario haya encontrado la información requerida en el catálogo, puede acceder a la recuperación de la información visual y sonora.

La información visual se almacenará, por el momento, de dos formas: digital (en discos CD-ROM que contienen información digitalmente codificada) y analógica (en videodiscos que contienen señales de video analógicas). Dibujos, gráficos y grabados se almacenarán digitalmente; colecciones fotográficas y películas, analógicamente. Para el almacenamiento digital se emplearán varias formas de digitilización.

Las colecciones textuales (los documentos escritos y manuscritos) se presentan en forma de facsímiles (imágenes de páginas o fotografias de páginas), en forma de texto reconvertido (bien escribiendo el texto de nuevo, bien mediante reconocimiento óptico de caracteres), o de ambos modos.

En el caso de las colecciones sonoras, American Memory pretende ampliar (a largo plazo) la duración normal de un compact-disc audio ( 72 minutos) mediante el uso de nuevas tecnologias de multimedios (CD-I DVI y CDROM XA), que le permitirán, a su vez, el almacenamiento de información visual, gráfica y textual.

A medida que el material se vea o se escuche, el sistema presentará al usuario la información textual pertinente. 
El material recuperado puede imprimirse o transportarse al módulo llamado "workshop". Dicho módulo of rece al usuario los mecanismos necesarios para la manipulación de imágenes y texto. Las imágenes digitalizadas y el texto pueden usarse directamente, mientras que las imágenes de vídeo (analógicas) tienen que digitalizarse antes mediante un convertidor. Este módulo permite al usuario crear su propia base de datos (textual y visual), manipular imágenes y texto con fines de publicación electrónica, etc.

Durante los primeros años del proyecto, las colecciones serán distribuidas mediante la duplicación de discos ópticos. En un futuro, cuando existan mayores avances tecnológicos y los costes de las telecomunicaciones desciendan, será posible difundir representaciones electrónicas del material requerido. En un plazo más lejano, la Biblioteca del Congreso espera poder of recer acceso en linea a las colecciones almacenadas a organizaciones e instituciones de todos los Estados Únidos.

Durante el periodo piloto, se integrarán en el sistema de quince a veinte colecciones cada tres años.

En 1992 la Biblioteca espera poder distribuir al menos dos colecciones. Hasta ese año el proyecto se encuentra en su fase de prueba. Se están realizando encuestas entre bibliotecarios, demostraciones a grupos profesionales, etc.

En las figuras 3-7 se ilustra, mediante una réplica de los gráficos del sistema prototipo, un posible uso de American Memory.

\section{Pigura 3}

El menú principal es una réplica de la planta del Edificio Thomas Jefferson de la Biblioteca del Congreso. En el prototipo, el usuario hace su selección apretando con el ratón la habitación donde desea ir. Los usuarios nuevos pueden seleccionar "Orientation Center" para conocer el contenido de American Memory y cómo funciona. En "Reading Room" se pueden hacer búsciuedas por medio del cat́álogo y registros individuales, u hojeando colecciones completas determinadas. En "Exhibit Hall" se lleva a cabo una presentación educacional basada en las colecciones de American Memory. Por último, en "Workshop" se puede trabajar con el material recuperado.

El botón "Stop" permite al usuario abandonar el sistema y "Help" conseguir ayuda en cada situación y contexto determinados.

Suponiendo que el usuario eligiera "Reading Room", lo siguiente que aparecería en el monitor sería la figura 4.

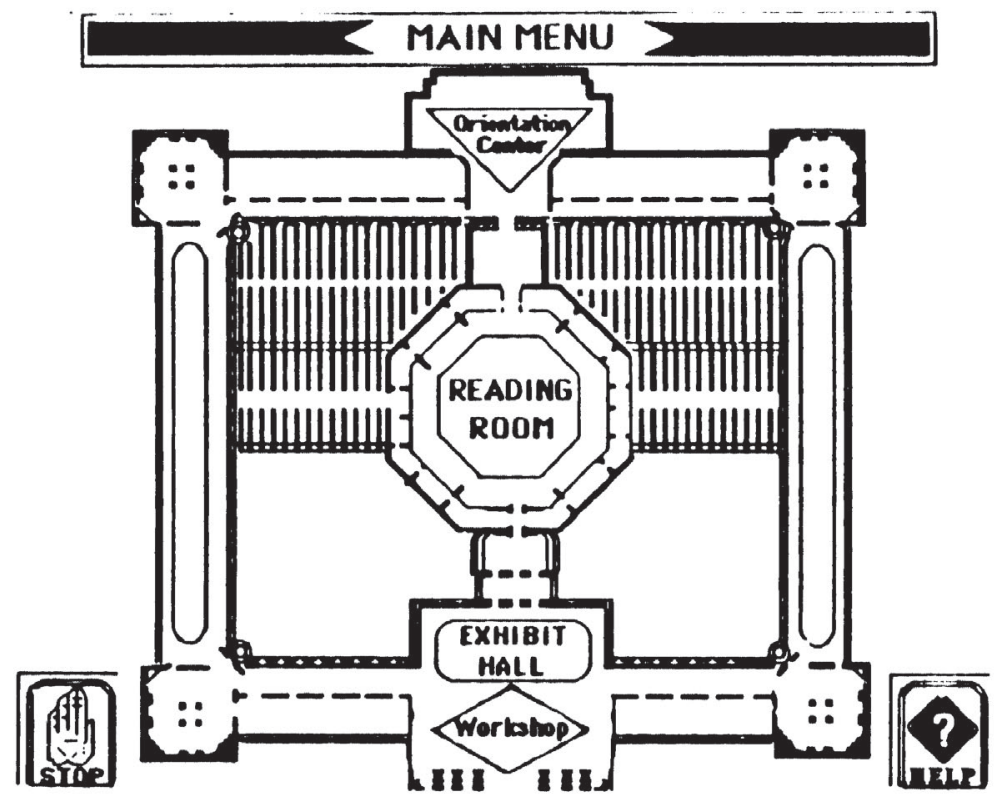




\section{Pioure 4}

En "Reading Room" se puede buscar en el catalogo de información relacionada con todas las colecciones fotográficas de American Memory, seleccionando con el ratón el área octogonal. Seleccionando los recuadros que representan distintos formatos, la bisqueda estaria limitada al formato seleccionado. El botón "Main" lleva al usuario al menú principal. "Print" imprime la pantalla. En el caso de que el usuario eligiera "photograph's", lo siguiente sería figura 5.

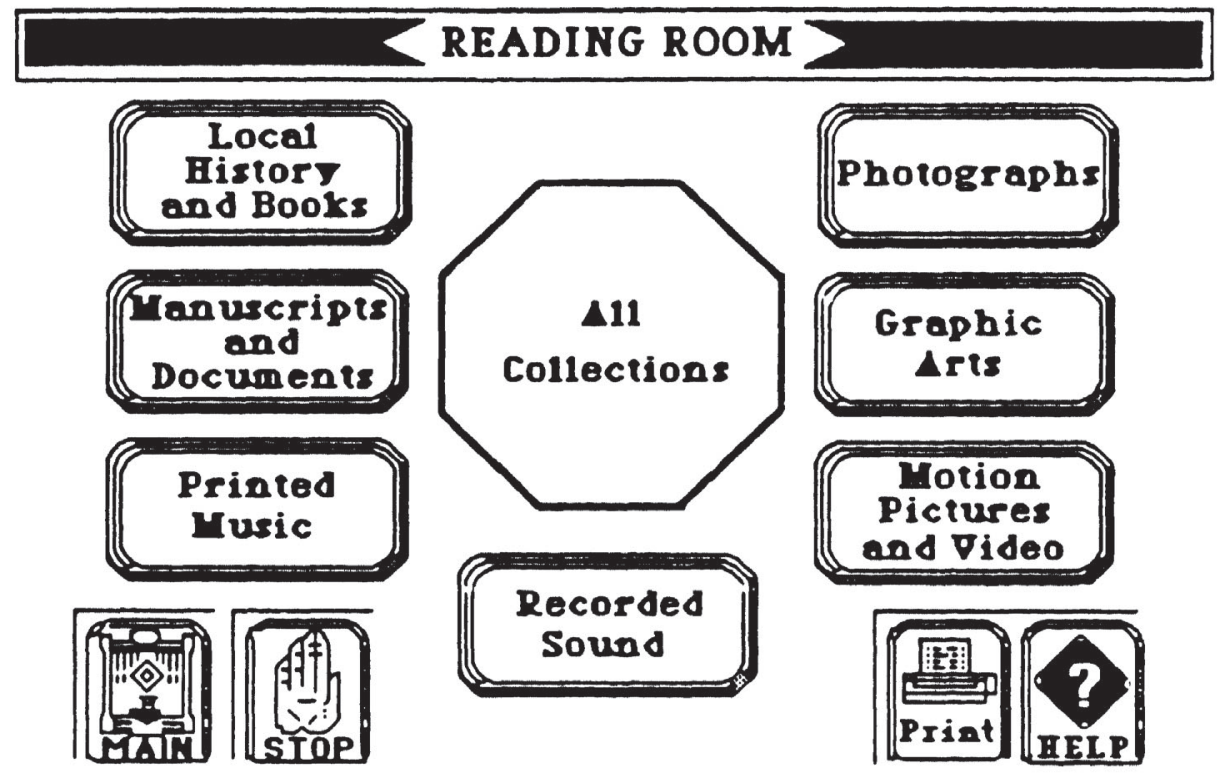

Pigure 5

De nuevo, se puede elegir entre buscar en todas las colecciones de American Memory, o en una colección determinada. Si eligiera la colección Detroit Publishing Company, figura 6.

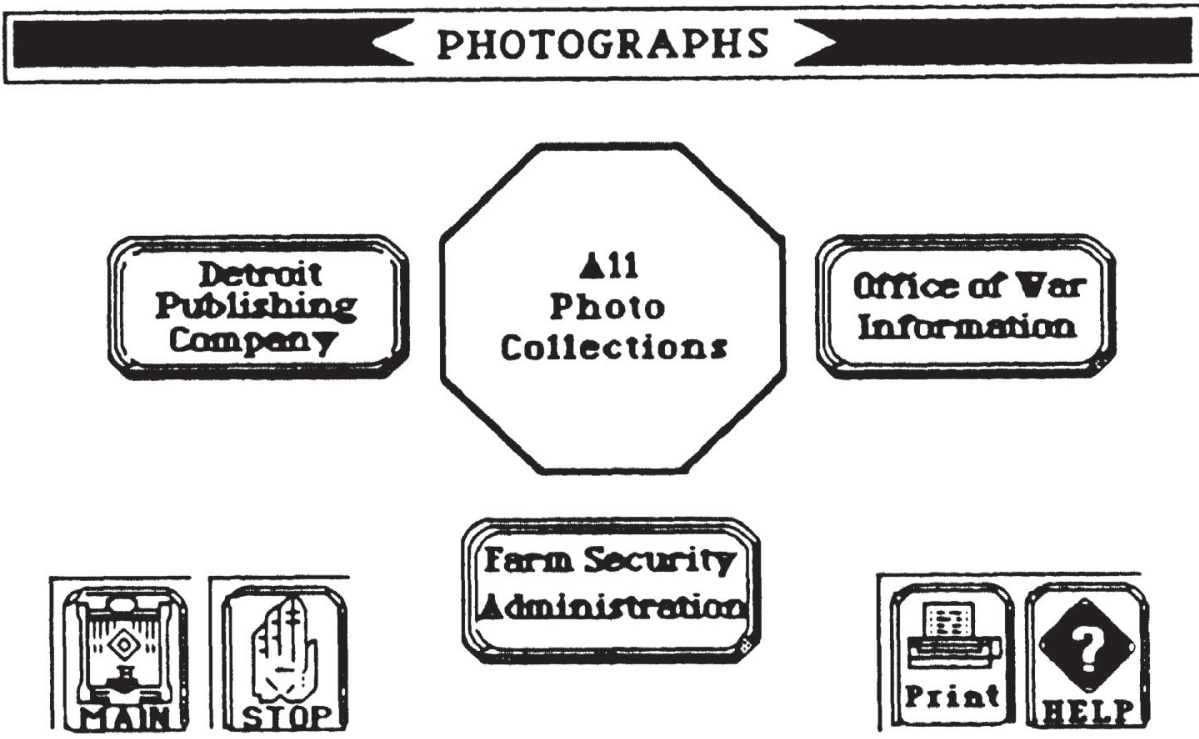

Rev. Esp. Doc. Cient.; 13, 3-4, 1990 


\section{Pigura 6}

La versión prototipo permite hacer la búsqueda mediante los operadores booleanos "and" y "or". La nueva versión prototipo permitirá también el operador "not" y la inclusión de más términos. En lugar de escribir directamente téminos de búsqueda conocidos el usuario puede recurrir a dos listas de términos que le sugieran términos de búsqueda: lista de todas las palabras contenidas en la base de datos seleccionada o un tesauro. En este caso, el tesauro sería Library of Congress Thesaurus for Graphic Materials: Topical Terms for Subject Access (Washington: Cataloguing Distribution Service, 1987). Si el usuario elige la primera lista, cada sección de ésta aparece en la pantalla de la derecha, y seleccionando con el ratón un término, automáticamente éste se insertaría en la ventana de búsquedas. El tesauro posibilita búsquedas más sofisticadas.

El botón "Browse" pasa del módulo de búsqueda al de hojear, que permite ver una por una las imágenes de cada colección.

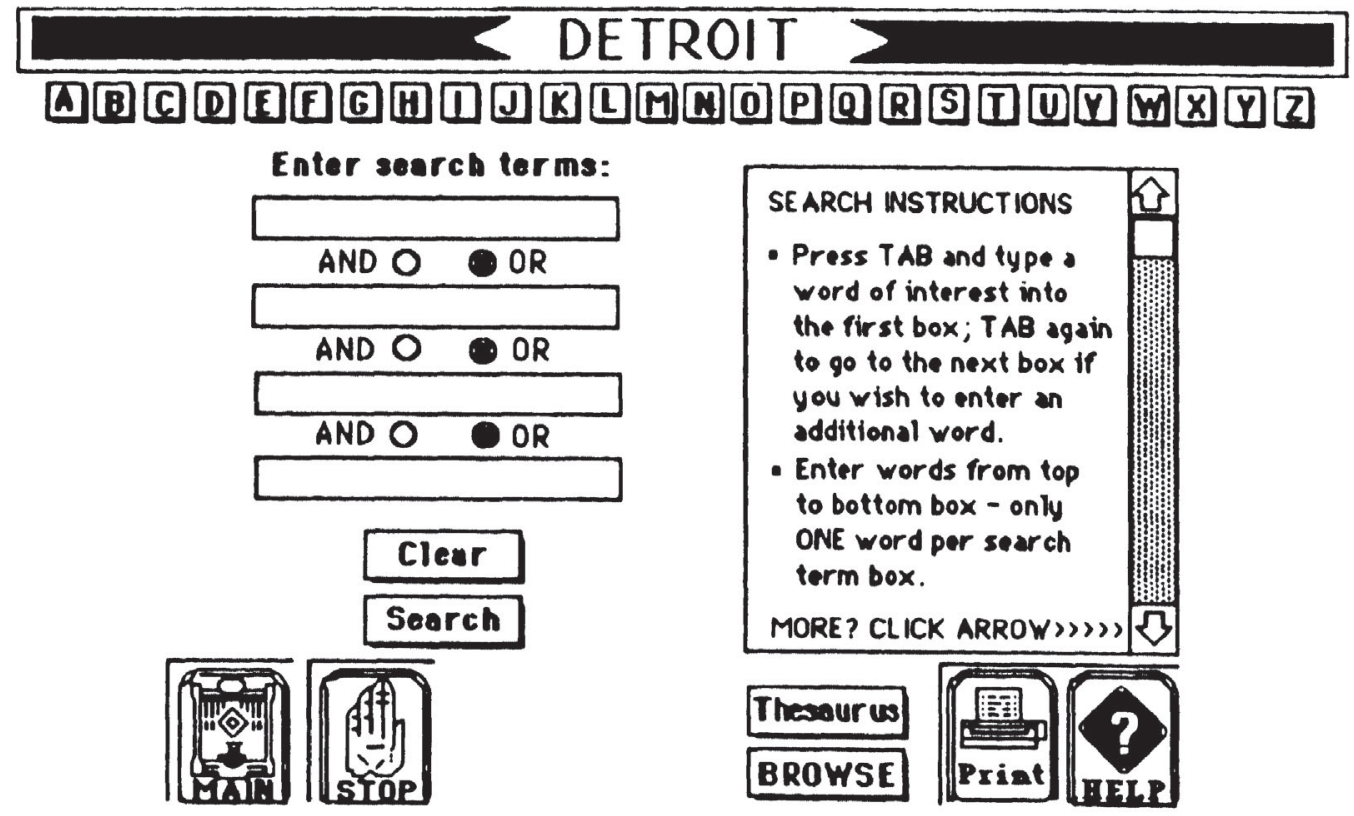

\section{Project Emperor-I}

Project Emperor-I es un sistema de hipermedios cuya información trata el descubrimiento arqueólogico de las figuras de terracota, del tiempo del primer emperador de China, Qin Shi Huang, hace aproximadamente 2200 años. El proyecto ha sido subvencionado por "Humanities Projects in Libraries, U.S. National Endowment for the Arts" y dirigido por Ching-chih Chen (13).

El proyecto comenzó en 1985 con la grabación de los dos videodiscos. En 1986-87 se diseñaron aplicaciones prototipo para sistemas IVIS, de Digital Equipment Corporation, e IBM XT, AT o compatibles. Sin embargo, al aparecer en 1987 el software "HyperCard" para Macintosh, el programa se comenzó a diseñar, en 1988, usando "HyperTalk" para microordenadores Macintosh Il. La versión china se ha llevado a cabo usando "ChincseTclk".

Los objetivos del proyecto son hacer de puente entre oriente y occidente, entre el pasado y el presente, entre las humanidades y la alta tecnologia, y entre la investigación y sus aplicaciones. 
Pigura 7

Esta pantalla ilustra una búsqueda de tres términos. Apretando el botón "Search" el usuario obtiene el número de resultados de su búsqueda, en este caso 1. El término "Lowell" ha sido seleccionado con la ayuda de la lista de términos de la base de datos. Si la búsqueda resulta en más de una imagen (en este caso), apretando el botón "First Card" se recupera la primera imagen, pudiendo seguir con el resto. Si se aprieta el botón "Title List", se obtiene una lista de los títulos del material seleccionado, y apretando con el ratón un título, se puede recuperar directamente, sin necesidad de ir imagen por imagen.

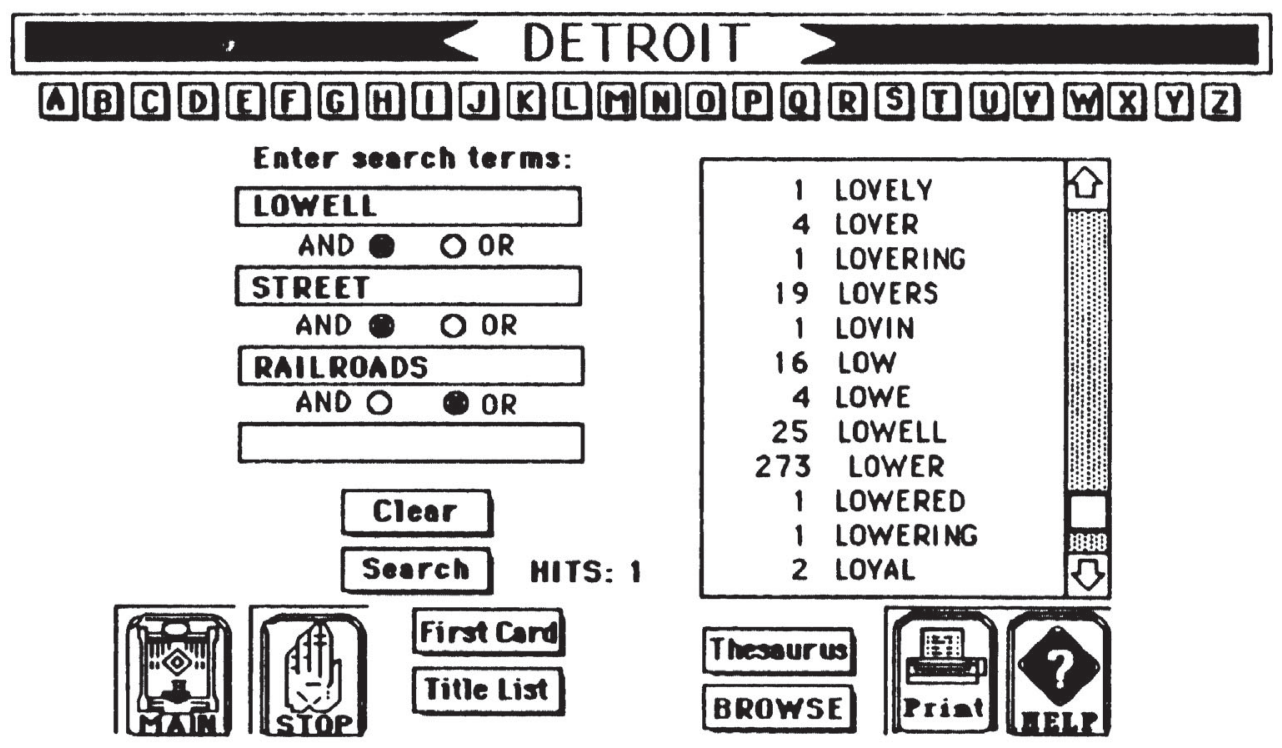

El hardware del sistema se compone de un microordenador Mac II, lector de videodisco e impresora. La información visual y sonora está almacenada analógicamente en dos videodiscos de dos caras. Cada uno de ellos contiene 108.000 cuadros de información visual (tanto imágenes estáticas como película) y una hora de banda sonora que incluye música, narraciones, y/o entrevistas con expertos en la materia. La parte narrada y las entrevistas pueden escucharse en inglés o en chino, según desee el usuario.

El primer videodisco contiene 200 segmentos de vídeo -convertido de grabaciones de películas y videocassettes-(figura 8) y 5.000 diapositivas. La información visual (acompañada de narración y música) está ordenada por capítulos, en forma de "libro electrónico". Cada uno de estos capitulos trata un tema; por ejemplo, "Introducción histórica al primer emperador de China", "La gran muralla china", "La excavación de las figuras de terracota", etc. Ei usuario puede recuperar la información visual y sonora bien por capítulos, bien por el número de cuadro asignado. 
Figura 8

Ejemplo de una de las imágenes contenidas en el primer videodisco

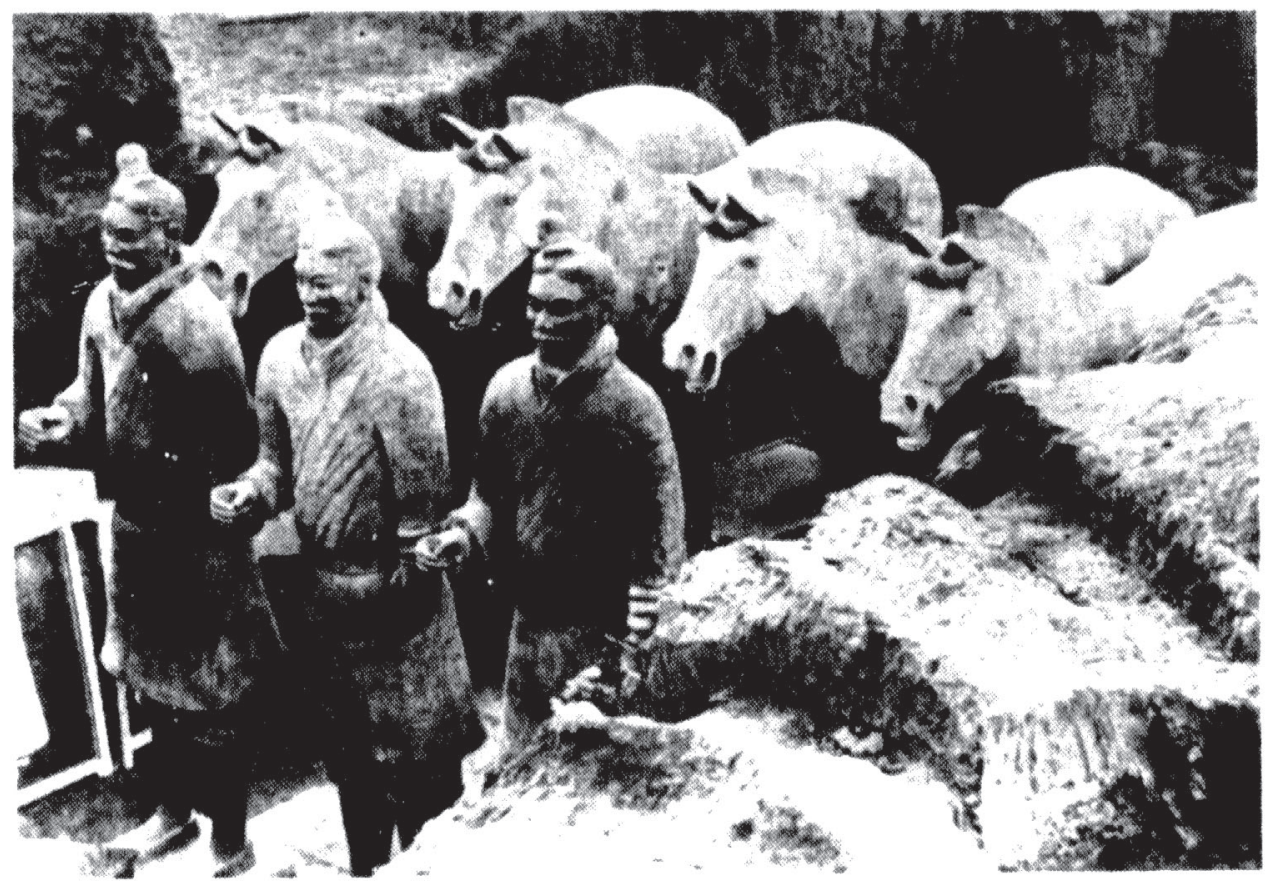

El segundo disco es esencialmente una historia oral e incluye las entrevistas a diez expertos en la materia. De nuevo, la información visual y sonora está ordenada por capítulos, según las preguntas históricas formuladas a cada investigador.

La figura 9 muestra el menú principal del proyecto, en inglés y en chino. Según el menú que elija el usuario, la información textual que aparece en el monitor es en inglés o en chino, pudiéndose cambiar en cualquier momento. El menú principal se compone de cinco módulos y tres fuentes de referencia. Los módulos son: controlador de videodisco, información general, investigación interactiva, exploración visual y búsqueda indizada. Las fuentes de referencia son: diccionario, bibliografía y mapas. Estas tres están almacenadas en el disco magnético, de forma que la información puede ampliarse $o$ modificarse cuando sea necesario, por ejemplo, incluyendo referencias a nuevos trabajos realizados. 
Figura 9

Menú principal, en inglés y chino

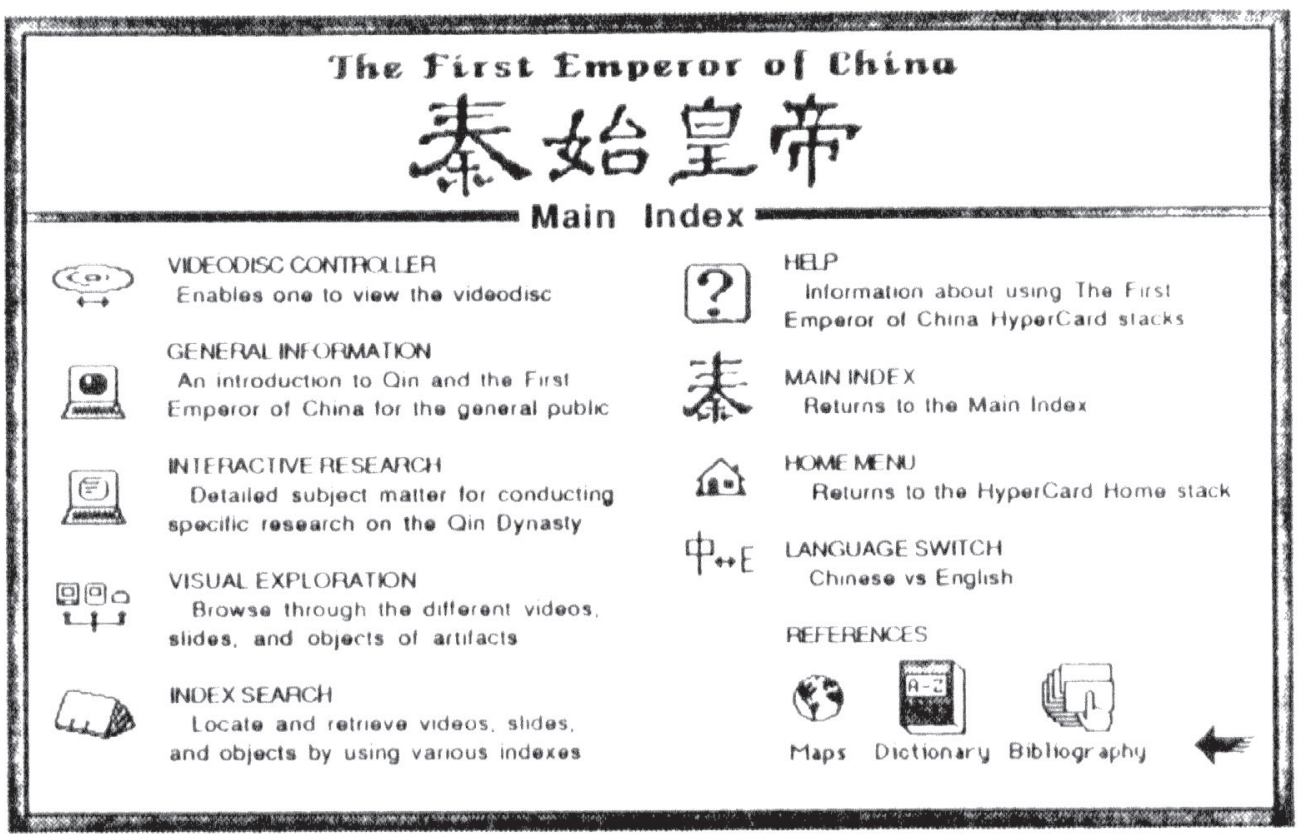

Figura 10

Controlador del videodisco

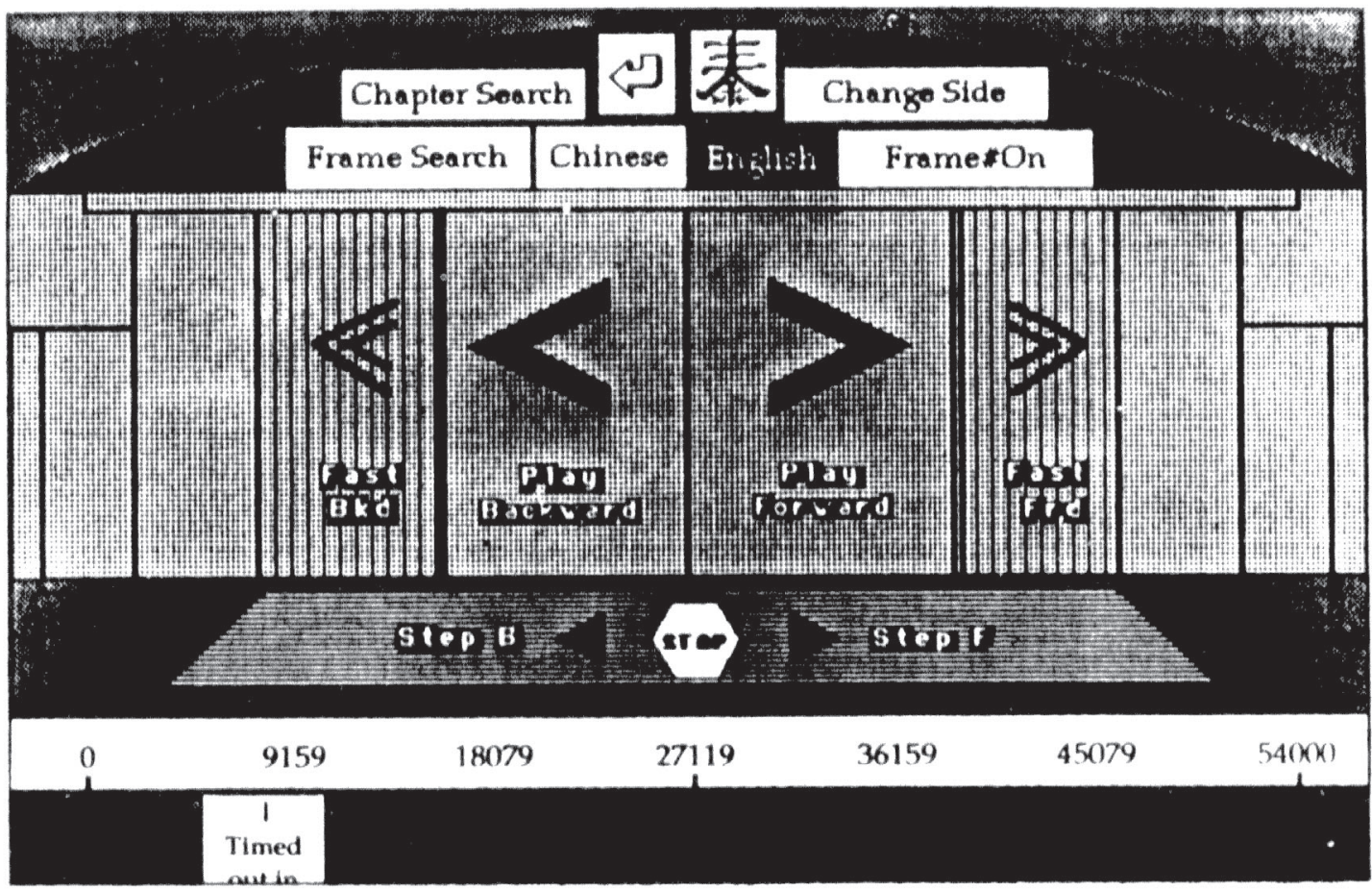


El controlador del videodisco (figura 10) permite al usuario recuperar la información almacenada en el mismo (vídeo e imágenes individuales) en el nivel 1 de interactividad: leer el video a velocidad normal, más rápido o más despacio, hacia delante o hacia atrás, cuadro a cuadro. Las imágenes pueden recuperarse bien a través de capitulos o del número de cuadro asignado. La narración correspondiente a la información visual aparece instantáneamente apretando el ratón.

Los cursos de información general están diseñados para el público general. Al elegir una materia, la información visual relevante almacenada en el videodisco aparece inmediatamente, junto con la información sonora y la información textual pertinente (en el monitor). Entrevistas con expertos sobre la materia seleccionada, diapositivas e información textual se recuperan seleccionando con el ratón el icono correspondiente. El usuario puede también obtener información sobre la localización geográfica de, por ejemplo, el área de la excavación seleccionando el icono que representa "Mapas", o puede buscar definiciones mediante la selección del icono que representa "Diccionario", o buscar bibliografia relacionada con la materia mediante la selección del icono que representa "Bibliografia". Al seleccionar bibliografia, el usuario tiene la posibilidad de, además de recuperar citas relevantes sobre la materia, recuperar los artículos enteros a los que las citas hacen referencia (salvo los que no se han podido incluir por motivo de copyright). Los articulos pueden imprimirse instantáneamente (enteros o sólo parte de ellos). El usuario también puede hacer sus propias anotaciones.

El módulo de investigación interactiva proporciona al usuario información más detallada acerca de la materia que elija (figura 11). Cada una de las materias se compone de varias submaterias, y se presenta en una, dos, o las tres funciones de información: textual, visual (diapositivas o pelicula) y sonora (entrevistas).

El módulo de exploración visual permite hojear rápidamente la colección de diapositivas almacenada en el videodisco, desplazarse a través de imágenes y pelicula (seleccionando determinadas partes para ampliarlas y volver de nuevo a su tamaño original), ir hacia delante o hacia atrás, y efectuar movimientos de rotación (de, por ejemplo, la imagen de un guerrero haciéndola visible desde todos los ángulos).

El módulo de búsqueda indizada capacita al usuario para recuperar información textual relacionada con cada diapositiva o segmento de video. Hay' seis formas de búsqueda: por fecha (del objeto o de su descubrimiento), por lugar (dónde se encuentra actualmente o dónde se descubrió), por tipo de material, por fuente de información, por materia, o por una combinación de estas cinco. Cada concepto puede ser subdividido y/o descrito por un modificador o descriptor. Así, si el usuario está interesado en recuperar la espalda de un soldado puede hacerlo, limitando la búsqueda mediante el modificador "espalda".

Project Emperor-I demuestra que las nuevas tecnologias aplicadas a los hechos históricos y arqueológicos pueden dar un acceso inmediato a la información, salvando barreras geográficas, politicas (en este caso, la mayoria de la información almacenada - grabaciones de las figuras arqueológicas, entrevistas con expertos, etc.- proviene de un país al que no es fácil acceder para investigar), y cronológicas. Demuestra, asimismo, que las nuevas tecnologías proporcionan una calidad de resolución en la información visual 
mucho mayor que la que se puede obtener, por ejemplo, en las reproducciones que se obtienen de China.

Figura 11

Menú del módulo de investigación interactiva

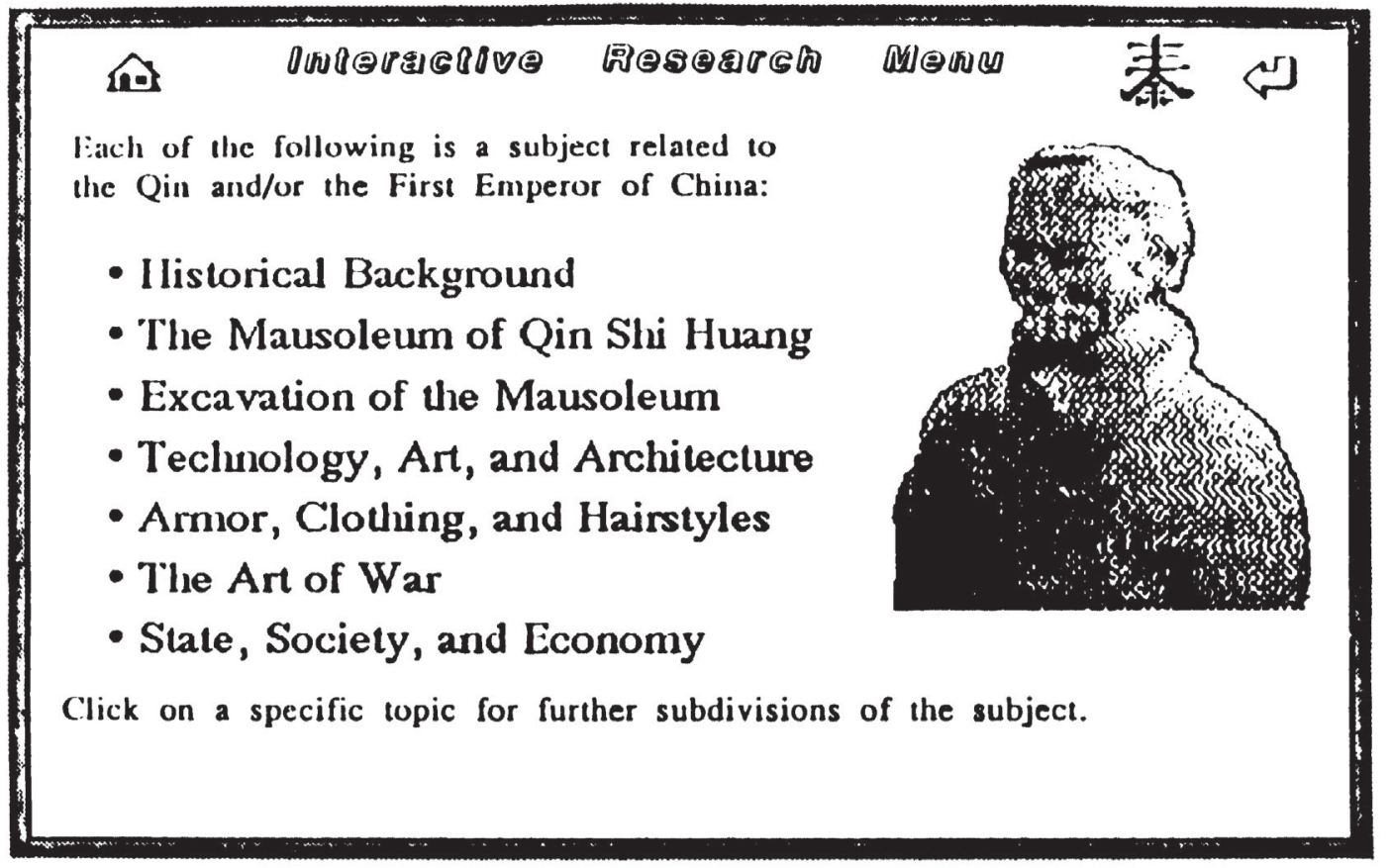

\section{Problemas de los sistemas de hipermedios}

Los sistemas de hipermedios of recen la posibilidad de almacenar y transmitir grandes cantidades de información de una forma más efectiva que los otros sistemas de información utilizados hasta ahora. Esto es, of recen la posibilidad de llegar a múltiples usuarios, la recuperación multidimensional de la información, la integración de información en múltiples medios, etc. Sin embargo, estos sistemas también presentan problemas que pueden hacer de ellos herramientas inútiles en la transmisión o difusión de información.

Entre los problemas más comunes destacan: pérdida y desorientación del usuario, incompatibilidad entre unos sistemas y otros, y posibilidad de proporcionar un conocimiento superficial e insuficiente.

El problema de la pérdida y desorientación es quizás el más palpable de todos (14). En los sistemas de hipermedios es fácil que el usuario se pierda, porque no entienda la estructuración de la información, porque no comprenda cómo desplazarse a través del sistema, porque no sepa exactamente dónde se encuentra y desconozca cómo volver "al buen camino", etc. Posibles soluciones a este problema consisten en proveer al sistema de capacidad de generar mapas globales que muestren al usuario las estructuras organizativas del sistema. Sin embargo, los mapas resultantes pueden ser tan complicados que desorienten más al usuario. Otra forma de resolver este problema es 
proporcionar módulos de ayuda que expliquen al usuario dónde se encuentra y las posibilidades que tiene de desplazarse por el sistema o de volver a un punto inicial siempre que lo necesite. El usuario tiene que comprender la estructuración del sistema, para lo cual el uso de un estilo coherente, la consistencia de las estructuras empleadas, la simplificación de los esquemas en pantalla, la coherencia del diseño de cada nivel informativo y las partes relacionadas, etc., son necesarios.

Otro grave problema de los sistemas de hipermedios es la incompatibilidad entre unos y otros. Nelson compara la compatibilidad de los documentos escritos con la incompatibilidad de los documentos electrónicos (softwares incompatibles, distintos formatos, etc.) (11). Esta incompatibilidad es también caracteristica de los sistemas de hipermedios. Nos encontramos ante lo que Van Dam llama "docu-islands" (15), es decir, sistemas que transmiten conocimiento y son incompatibles unos con otros. Cada sistema tiene su propia estructuración, está organizado siguiendo distintos modelos, etc. No existen modelos normalizados de desarrollo de sistemas de hipermedios.

El otro gran problema se da en la relación "recuperación de información conocimiento adquirido". Doland destaca la posibilidad de que el usuario malinterprete el sentido de la estructuración del sistema (16). El hecho de moverse de pantalla en pantalla puede conllevar la adquisición de un conocimiento superficial. Video y sonido pueden suponer también una recuperación pasiva del conocimiento. Los sistemas de hipermedios están concebidos para ser experimentados interactivamente, y no para ser impresos. Si el usuario imprime determinadas partes del sistema puede interpretarlo como superficial, al no ser consciente de la argumentación implicita creada por los enlaces entre los distintos nudos informativos. Los sistemas están pensados para que el usuario hojee y se desplace por el sistema, por lo que un entendimiento incompleto de las asociaciones creadas le lleva a malinterpretar el sentido de la estructuración.

La cantidad de información acumulada es otro problema, ya que el usuario tiene que preguntarse constantemente qué enlaces seguir y cuáles ignorar.

\section{Reflexión fina!}

En el "hipermundo" que describe Nelson, "los documentos se vinculan libremente unos con otros, cualquier cita puede rastrearse y verse en su contexto original, en cualquier parte se pueden encontrar interpretaciones minoritarias y comentarios, se pueden discutir puntos de vista contrarios en "el margen", un mosaico de partes puede ser estructurado por cualquiera en una nueva visión unificadora..." (17).

Sin duda, este "hipermundo" presenta un panorama fascinante. Por primera vez en la historia de la biblioteconomia y la documentación existe la posibilidad de transmitir, de una forma no lineal, información en múltiples medios.

No son pocas las funciones que convierten a los sistemas de hipermedios en medios ideales para transmitir información con determinados fines y aplicaciones: acceso no predeterminado a la información; riqueza, flexibilidad y no linealidad en la estructuración; integración de información de múltiples medios dentro del mismo sistema; manipulación de la información para varios 
usos; utilidad para distintos tipos de usuario; interactividad con el usuario; etcétera.

Sin embargo, es importante tener en cuenta que estos sistemas están aún en un estadio inicial de su desarrollo. Es necesario, además de solucionar los problemas citados en el apartado anterior, investigar las repercusiones de estos sistemas sobre las nuevas generaciones (por ejemplo, una posible pérdida de familiaridad con el formato del libro).

Estamos en la primera generación de usuarios y en la primera, también, de creadores de sistemas de hipermedios. Es de esperar que parte de los problemas que presentan hoy sean resueltos por futuras generaciones de usuarios más familiarizados con la recuperación de grandes cantidades de información por medio de sistemas no lineales.

Hasta entonces, se requieren estudios profundos e investigación experimental para aprovechar al máximo un mundo de asociaciones infinitas cuya existencia intuyó Vannevar Bush ya hace cuarenta y cinco años y que sólo el desarrollo de la tecnología haría posible.

Ese mundo ya existe. A nosotros nos corresponde explorarlo.

\section{Bibliografía}

1. BUSH,. As we may think. Atlantic Monthly 101-108, julio, 1945.

2. ENGELBART, D. A conceptual framework for the augmentation of man's intellect. Vistas in Information Handling, vol. 1. Washington, DC: Spartan Books. 1.

3. ENGELBART, D.; English, W.K. A research center for augmenting human intellect. AFIPS Proceedinss, Fall Joint Computer Conference. 1968.

4. NELSON, T. Replacing the printed word: A complete library syatem. IFIP Proceedings, octubre, 1980.

5. NELSON, T. H. A conceptual framework for man-machine everything. 1973 National Computer Conference and Exposition, June 4-8, 1973, New York, AFIPS Conference Proceedinge, Volume 42. (Montvale, N.J.: AFIPS Prese 1973), p. M22-M23.

6. BYERS, T.J. Built by association. PC World $5,250,1987$.

7. GAINES, B. R.; VICKERS, J. N. Designs considerations for hypermedia systems. Microcomputers for Information Manazement 5 (1), 1-28, 1988.

8. RAITT, D. Panorama del CD-I y del DVI. Revista Espanola de Documentación Cientifica 13 (1) 694-599, 1990.

9. CONKLIN, J. Hypertext: An introduction and survey. Computer 20, 17-41, 33, 1987

10. PARSAYE, $K$., et al. Intelligent Databases: Object Orienied, Deductive Hypermedia Technolories. New York, NY: John Wiley \& Sons, 1989, 244-245.

11. NELSON, T.H. Unifying tomorrow's hypermedia. Proceedinge of the 12th International Online Information Meetins, London, December 6-8, 1988. Oxford: Learned Information, 1988, 1-7.

12. American Memory from the Library of Congress. Trabajo no publicado, 15p.

13. CHEN, C. As we think: Thriving in the hyperweb environment. Microcomputers for Information Manazement 6 (2), 77-97, 1989.

CHEN, C. The First Emperor of China's ancient world uncovered: From Xian to your electronic screen. Academic Computing 3 (7), 10-14, 54-56, 1989.

14. EDWARDS, D. M. HARDMAN, L. Lost in Hyperspace: Cognitive mapping and navigation in a hypertext environment. Hypertext: Theory into Practice, ed. R. McAleese. Norwood (n.J.): Ablex, 105-125, 1989.

16. VAN DAM, A. Hypertext'87 keynote address. Communications of the ACM 31, 894, 1988.

16. DOLAND, V. Hypermedia as an interpretative act. Hypermedia 1 (1), 6-19, 1989.

17. NELSON, T.H. A new home for the mind. Documentation 28 (3), 169-180, 1982. 